\title{
Conference Issues Vs. Conference Proceedings
}

\author{
K. Kampourakis ${ }^{1}$
}

Published online: 30 August 2017

(C) Springer Science+Business Media B.V. 2017

It is a common practice for many journals, including Science \& Education, to publish issues that include articles that stem from related conferences. Especially when a journal has a special affiliation with a group, as it is the case for Science \& Education and the International History, Philosophy and Science Teaching (IHPST) group, one would expect the members of the group participating in a conference to submit their conference papers to their journal in order to pursue publication. However, a crucial distinction is not always made clear: that between conference issues and conference proceedings.

Let us start with the latter. Conference proceedings are collections of papers presented in a conference that may be published in a book or a website form. In some cases, the papers are submitted before the conference, and thus the proceedings are accessible to participants; in other cases, the proceedings are published after the conference and after the authors have received feedback during the sessions. There are advantages and disadvantages in both cases. When the proceedings are published before the conference and are available during it, the advantage is that conference participants can look at the papers they are interested in and find out more than what one can present in 20 minutes. When the proceedings are published after the conference, they usually include improved versions of the papers as authors have also considered the feedback of colleagues and revised them accordingly. Conference proceedings are generally good to have before or after the conference.

However, getting published in a journal is a different story. And when conference papers evolve to journal articles, as it is the case for the articles of the present volume, the process is long and demanding. Conference volumes, like this one stemming from the 2016 regional IHPST conference in Flensburg, are not conference proceedings. To explain the difference, I will describe the process that takes place, and that in this case resulted in the present volume. As in many previous IHPST conferences, one member of the editorial team of Science \& Education attended the IHPST conference and encouraged participants to submit to the journal. The conference organizing committee also did the same. However, there was no

K. Kampourakis

Kostas.Kampourakis@unige.ch

1 Section of Biology and IUFE, University of Geneva, Pavillon Mail, 40 Boulevard du Pont-d'Arve, 1211 Geneva 4, Switzerland 
previous commitment that a conference volume would be published because this cannot be known in advance. Various authors thus submitted their papers to the journal.

No matter how high the standards of the conference organizers were and how rigorous the review process they implemented was, a research journal is an independent entity. Therefore, we received and processed the Flensburg papers as any other submission, applying the review processes that we normally apply, which have (for good or bad) resulted to a rejection rate around $70 \%$. A journal article must have several qualities that are not necessary for a conference paper, and so we must ensure that the submitted papers meet these criteria. Therefore, after the standard review process that all articles submitted to Science \& Education undergo, the six articles included in the present volume were accepted for publication in the journal. To highlight that these are not unsolicited submissions but IHPST conference papers that evolved to journal articles through the hard work of their authors, I have decided to have them published independently. The authors had to work about a year on these articles and undergo at least two rounds of rigorous review to make it in the pages of the present volume. Congratulations!

The organizers of the Flensburg conference, Peter Heering and Claus Michelsen, also deserve a special acknowledgement for working for this volume. One of them was a reviewer for each submitted paper related to the conference, and there were many submissions to review. I thank them for all their hard work.

\section{Compliance with ethical standards}

Conflict of Interest The author declares no conflict of interest. 